\title{
Prognostic role of matrix metalloproteinases in bladder carcinoma: a systematic review and meta-analysis
}

\author{
Chenkui Miao ${ }^{1, *}$, Chao Liang ${ }^{1, *}$, Jundong Zhu ${ }^{1, *}$, Aiming Xu${ }^{1}$, Kai Zhao ${ }^{1}$, Yibo Hua ${ }^{1}$, \\ Jianzhong Zhang ${ }^{1}$, Wei Chen ${ }^{2}$, Chuanjian Suo ${ }^{1}$, Chao Zhang ${ }^{1}$, Yiyang Liu ${ }^{1}$, Shifeng \\ $\mathrm{Su}^{1}$ and Zengjun Wang ${ }^{1}$ \\ ${ }^{1}$ State Key Laboratory of Reproductive Medicine and Department of Urology, The First Affiliated Hospital of Nanjing Medical \\ University, Nanjing, People's Republic of China \\ 2 Department of Urology, Nanjing First Hospital, Nanjing Medical University, Nanjing, People's Republic of China \\ * These authors have contributed equally to this work \\ Correspondence to: Zengjun Wang, email: zengjunwang@njmu.edu.cn
}

Shifeng Su, email: shifengsu@gmail.com

Keywords: matrix metalloproteinases, bladder cancer, prognosis, meta-analysis

Received: September 06, $2016 \quad$ Accepted: February 21, $2017 \quad$ Published: March 04, 2017

Copyright: Miao et al. This is an open-access article distributed under the terms of the Creative Commons Attribution License (CC-BY), which permits unrestricted use, distribution, and reproduction in any medium, provided the original author and source are credited.

\section{ABSTRACT}

Recent studies have shown that matrix metalloproteinases (MMPs) might be a biomarker for predicting outcomes of bladder cancer. However, the prognostic value of overexpression of MMPs in bladder cancer is debatable and the studies are inconsistent. Therefore, this meta-analysis was performed to clarify the specific association and prognostic value of overexpression of MMPs in bladder carcinoma. Relevant studies were identified by searching PubMed, EMBASE, and the Web of Science. Pooled hazard ratios (HRs) with $95 \%$ confidence intervals (CIs) for diseasespecific survival (DSS), overall survival (OS), disease/recurrence-free survival (DFS/RFS), and progression/metastasis-free survival (PFS/MFS) were analyzed to determine the prognostic value of MMPs. In total, eighteen applicable studies were included in this meta-analysis. We found that high expression of MMPs significantly correlated with a poor DSS and OS $(H R=1.66 ; 95 \% \mathrm{CI}=1.38-2.01$ and $H R=1.67$; $95 \% \mathrm{CI}=1.26-2.22)$. MMPs also predicted tumor progression and metastasis with a pooled HR of 3.03 (95\% CI 1.98-4.64). However, high MMPs expression had no pivotal impact on DFS/RFS (HR= 1.21; 95\% CI= 0.96-1.53). With the purpose of better understanding the prognostic role of MMPs in patients wirh bladder carcinoma, we carried out this systematic review and meta-analysis.

\section{INTRODUCTION}

Despite a declining occurrence rate in recent years, bladder cancer is still the most frequent malignancy of the urinary system worldwide. Its incidence had risen to be the ninth most common malignant tumor in 2008 [1]. Approximately 386, 000 new cases of bladder carcinoma and 150, 000 disease-specific deaths occur worldwide every year [2]. Recent studies have shown that around $30 \%$ of bladder cancer cases are muscle invasive bladder cancers (MIBC) while the other approximately $70 \%$ are non-muscle invasive bladder cancers (NMIBC) $[3,4]$.
Although some progress has been made in therapeutic approaches for bladder cancer, patients still experienced poor survival outcome, with high recurrence and mortality. The pathogenesis and progression of bladder cancer is complicated, and its occurrence and development seem to be influenced by many factors, such as multiple genes and external environmental factors $[5$, 6]. To improve the quality of patients' individual care, it is essential to investigate prognostic factors for survival and recurrence of bladder cancer and identify novel techniques for diagnosis and treatment [7].

Matrix metalloproteinases (MMPs) family belongs to more than 25 zinc-dependent endogenous proteolytic 
enzymes and they have significant influences on tumor invasion and migration, such as extracellular matrix (ECM) degradation, loss of cellular adhesion, tumor angiogenesis, epithelial-to-mesenchymal transitions, and cellular proliferation $[8,9]$. Recently, increasing evidence has verified that the activity of MMPs plays pivotal role in several physiological and pathological processes, such as the development of multiple carcinomas and angiocardiopathy [10-13]. There are numerous subtypes of MMPs, such as MMP1, MMP2, MMP3, MMP7, MMP9, and MMP14. Many of studies have evaluated levels of MMPs extensively in cancer patients, and reported vital roles of some MMPs as diagnostic and prognostic biomarkers in tumorigenesis. Previous systematic reviews have demonstrated that certain MMPs subtypes are associated with a poor outcome in stomach, breast, and ovarian cancer $[14,15]$. Additionally, a number of basic and clinical studies have shown an relationship between MMPs and shortened survival in bladder cancer patients [16].

However, a few individual studies have proposed contradictory conclusions. For instance, Vasala et al. reported that increased expression of MMP9 correlated with longer overall survival and decreased recurrence rates of urinary bladder cancer. MMP9 may therefore serve as a favorable biomarker and its overexpression may predict better outcomes in bladder cancer patients [17]. The results was still controversial due to several limitations: small sample sizes, lower statistical veracity, and genuine heterogeneity. Therefore, we carried out a systematic review and meta-analysis to clarify the relevance of abnormal levels of MMPs on outcomes in patients with bladder carcinoma.

\section{RESULTS}

\section{Summary of enrolled studies}

As is shown in Figure 1, a total of 262 studies from PubMed, EMBASE, and the Web of Science were found to focus on the relationship between MMPs expression and bladder carcinoma. After initial screening of titles and abstracts, 159 studies were excluded because: they did not focus on the specific association of MMPs expression and bladder cancer, were review articles or non-English articles, or did not include human subjects. After applying this criteria to filter the remaining 103 studies, 85 potentially suitable studies were excluded because they lacked sufficient survival data (HRs and 95\% CIs), were not relevant to the outcome analysis, did not report comprehensive data, or had reduplicative data sets. Ultimately, eighteen studies were considered applicable to this meta-analysis. The inclusion and exclusion reasons for the screened studies are summarized in detail in Figure 1.

Dominant features and results of the appropriate articles are listed in Table 1 and Table 2. To sum up, all studies included were published from 1996 to 2016 . These studies investigated the association between bladder

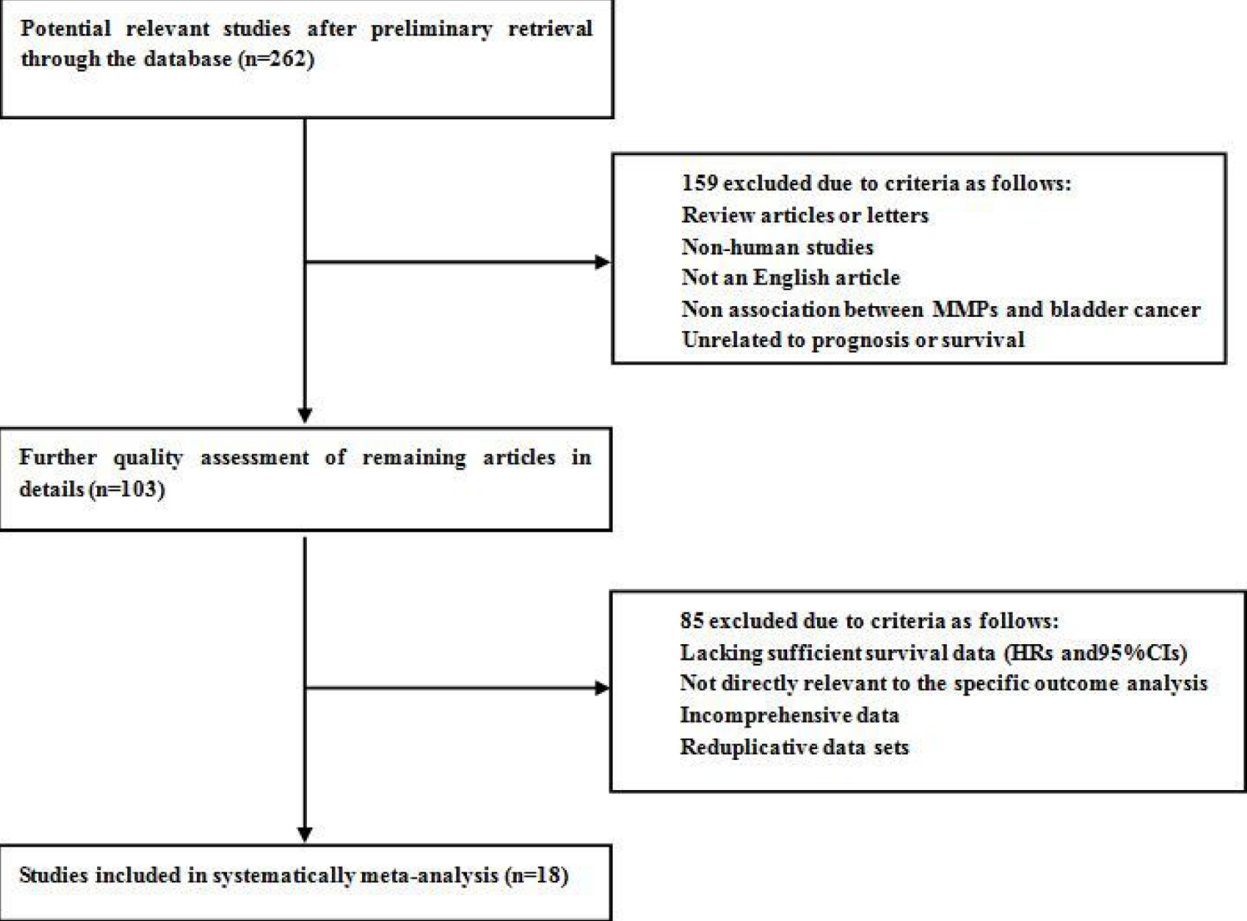

Figure 1: Flow diagram of literature search and selection process. 
Table 1: Main characteristics of studies included in the meta-analysis.

\begin{tabular}{|c|c|c|c|c|c|c|c|c|c|}
\hline $\begin{array}{l}\text { First author, } \\
\text { publication year }\end{array}$ & $\begin{array}{l}\text { MMP } \\
\text { types }\end{array}$ & $\begin{array}{l}\text { Case } \\
\text { nationality }\end{array}$ & $\begin{array}{l}\text { Dominant } \\
\text { ethnicity }\end{array}$ & \begin{tabular}{|l} 
Median \\
or \\
mean \\
age
\end{tabular} & $\begin{array}{l}\text { Study } \\
\text { design }\end{array}$ & $\begin{array}{l}\text { Detected } \\
\text { sample }\end{array}$ & $\begin{array}{l}\text { Survival } \\
\text { analysis }\end{array}$ & $\begin{array}{l}\text { Source of } \\
\text { HR }\end{array}$ & $\begin{array}{l}\text { Maximum } \\
\text { months of } \\
\text { follow-up }\end{array}$ \\
\hline Li, 2016 & MMP11 & China & Asian & 65.8 & $\mathrm{R}$ & tissue & DSS/MFS & Reported & 175.8 \\
\hline Minami, 2014 & MMP2 & Japan & Asian & 71 & $\mathrm{R}$ & serum & DSS/RFS & Reported & 166.4 \\
\hline Demery, 2014 & MMP7 & France & Caucasian & 69 & $\mathrm{R}$ & serum & OS & Reported & 194.4 \\
\hline Olsson, 2012 & MMP2 & Sweden & Caucasian & 73 & $\mathrm{R}$ & tissue & RFS/PFS & Reported & 192 \\
\hline Olsson, 2012 & MMP9 & Sweden & Caucasian & 73 & $\mathrm{R}$ & tissue & RFS & Reported & 192 \\
\hline Szarvas, 2011 & MMP7 & Germany & Caucasian & 65 & $\mathrm{R}$ & serum & OS/DSS/MFS & Reported & 148 \\
\hline Svatek, 2010 & MMP1 & America & Caucasian & 64 & $\mathrm{R}$ & serum & DSS & Reported & 50 \\
\hline Svatek, 2010 & MMP2 & America & Caucasian & 64 & $\mathrm{R}$ & serum & DSS & Reported & 50 \\
\hline Svatek, 2010 & MMP3 & America & Caucasian & 64 & $\mathrm{R}$ & serum & DSS & Reported & 50 \\
\hline Svatek, 2010 & MMP7 & America & Caucasian & 64 & $\mathrm{R}$ & serum & DSS & Reported & 50 \\
\hline Svatek, 2010 & MMP8 & America & Caucasian & 64 & $\mathrm{R}$ & serum & DSS & Reported & 50 \\
\hline Svatek, 2010 & MMP9 & America & Caucasian & 64 & $\mathrm{R}$ & serum & DSS & Reported & 50 \\
\hline Szarvas, 2010 & MMP7 & Germany & Caucasian & 65 & $\mathrm{R}$ & serum & OS/DSS/MFS & Reported & 196 \\
\hline Sagara, 2010 & MMP14 & Japan & Asian & 71 & $\mathrm{R}$ & tissue & DSS/MFS & $\mathrm{SC}$ & 195 \\
\hline Vasala, 2003 & MMP9 & Finland & Caucasian & 67 & $\mathrm{R}$ & tissue & OS/DSS/RFS & $\mathrm{SC}$ & 120 \\
\hline Slaton, 2004 & MMP9 & America & Caucasian & 65.5 & $\mathrm{R}$ & tissue & DSS & Reported & 168 \\
\hline Vasala, 2003 & MMP2 & Finland & Caucasian & 66 & $\mathrm{R}$ & tissue & OS/DSS/RFS & $\mathrm{SC}$ & 120 \\
\hline Durkan, 2003 & MMP9 & England & Caucasian & 70 & $\mathrm{R}$ & tissue & DSS/PFS & Reported & 39 \\
\hline Durkan, 2001 & MMP1 & England & Caucasian & 70 & $\mathrm{R}$ & urine & DSS/PFS & $\mathrm{SC}$ & 39 \\
\hline Nakopoulou, 2001 & MMP3 & Greece & Caucasian & 70 & $\mathrm{R}$ & tissue & OS & $\mathrm{SC}$ & 65 \\
\hline Hara, 2001 & MMP9 & Japan & Asian & 65 & $\mathrm{R}$ & tissue & RFS & $\mathrm{SC}$ & 39 \\
\hline Kanayama, 1998 & MMP2 & Japan & Asian & 69.7 & $\mathrm{R}$ & tissue & DSS & $\mathrm{SC}$ & 85.8 \\
\hline Gohji, 1998 & MMP2 & Japan & Asian & 59 & $\mathrm{R}$ & serum & DSS & $\mathrm{SC}$ & 60 \\
\hline Gohji, 1996 & MMP3 & Japan & Asian & 57 & $\mathrm{R}$ & serum & DSS & $\mathrm{SC}$ & 100 \\
\hline
\end{tabular}

Study design is described as retrospective (R); MMPs, matrix metalloproteinases.

OS, overall survival; DSS, disease-specific survival; DFS, disease-free survival; RFS, recurrence-free survival; PFS, progression-free survival; MFS, metastasis-free survival.

$\mathrm{SC}$, survival curve.

cancer and multiple MMPs types. Among these, there are seven studies focusing on MMP2, six studies focusing on MMP9, four articles concentrating upon MMP7, and three articles on MMP3. Furthermore, there exist two articles regarding MMP1, and one article each on MMP8, MMP11, and MMP14. Eleven of the studies focused on Caucasian populations, which mainly came from European countries, and seven focused on Asian populations, of which six from Japan primarily and one from China.

Six studies reported patient overall survival (OS), fourteen focused on disease-specific survival/cancer specific survival (DSS/CSS), five studies covered disease/ recurrence-free survival (DFS/RFS), while another five articles investigated progression/metastasis-free survival (PFS/MFS). In addition, all of included studies were retrospective in design, and the maximal follow-up period ranged from 39 to 192 months.
Tissue samples were used to determine MMPs expression in ten studies, serum samples were used in seven studies, and urine samples were used in one study. Enzyme linked immunoassay (ELISA) and immunohistochemistry (IHC) were used in the majority of all eligible studies to detect MMPs expression. A few studies used northern blots, reverse transcriptasequantitative polymerase chain reaction (RT-qPCR), or an enzyme immunoassay (EIA). Although a few articles did not mention the cut-off point defining MMPs expression, median/mean value served as the dividing grade in most included studies.

\section{OS associated with MMPs expression}

Among the seven studies reporting OS, a fixedeffects model was used to analyze the data because of 
Table 2: HRs and 95\% CIs of patient survival or cancer progression relating to MMPs expression in eligible studies.

\begin{tabular}{|c|c|c|c|c|c|c|c|c|c|c|c|c|c|}
\hline \multirow{2}{*}{$\begin{array}{l}\text { First author, } \\
\text { publication } \\
\text { year }\end{array}$} & \multirow{2}{*}{$\begin{array}{l}\text { MMP } \\
\text { types }\end{array}$} & \multirow{2}{*}{$\begin{array}{l}\text { Main } \\
\text { assay } \\
\text { method }\end{array}$} & \multirow{2}{*}{$\begin{array}{l}\text { Cut-off } \\
\text { value }\end{array}$} & \multicolumn{2}{|c|}{ Case number } & \multicolumn{2}{|l|}{ OS } & \multicolumn{2}{|l|}{ DSS/CSS } & \multicolumn{2}{|l|}{ DFS/RFS } & \multicolumn{2}{|l|}{ PFS/MFS } \\
\hline & & & & $\begin{array}{l}\text { High } \\
\text { expression }\end{array}$ & $\begin{array}{l}\text { Low } \\
\text { expression }\end{array}$ & HR(95\%CI) & $\begin{array}{l}P \\
\text { value }\end{array}$ & HR(95\%CI) & $P$ value & HR(95\%CI) & $\begin{array}{l}P \\
\text { value }\end{array}$ & HR(95\%CI) & $\begin{array}{l}P \\
\text { value }\end{array}$ \\
\hline Li, 2016 & MMP11 & $\mathrm{IHC}$ & median & 170 & 170 & NM & NM & $\begin{array}{l}3.027(1.406- \\
6.516)\end{array}$ & 0.005 & NM & NM & $\begin{array}{l}2.261(1.149- \\
4.45)\end{array}$ & 0.018 \\
\hline Minami, 2014 & MMP2 & ElISA & mean & 48 & 47 & NM & NM & $\begin{array}{l}2.62(1.04- \\
6.58)\end{array}$ & 0.04 & $\begin{array}{|ll|}0.77 & (0.33- \\
1.81) & \\
\end{array}$ & $>0.05$ & NM & NM \\
\hline Demery, 2014 & MMP7 & ElISA & mean & 16 & 39 & 2.1(1.1-4.4) & 0.035 & NM & NM & NM & NM & NM & NM \\
\hline Olsson, 2012 & MMP2 & $\mathrm{IHC}$ & NM & 18 & 185 & NM & NM & NM & NM & \begin{tabular}{|l|}
1.27 \\
$1.92)$
\end{tabular} & 0.27 & NM & NM \\
\hline Olsson, 2012 & MMP9 & $\mathrm{IHC}$ & NM & 38 & 163 & NM & NM & NM & NM & $\begin{array}{|ll|}1.56 & (1.01- \\
2.38) & \\
\end{array}$ & 0.046 & NM & NM \\
\hline Szarvas, 2011 & MMP7 & ElISA & mean & 46 & 32 & $\begin{array}{l}2.264(1.235- \\
4.148)\end{array}$ & 0.008 & $\begin{array}{l}1.906(1.006- \\
3.614)\end{array}$ & 0.048 & NM & NM & $\begin{array}{l}2.037(0.625- \\
6.636)\end{array}$ & 0.238 \\
\hline Svatek, 2010 & MMP1 & ElISA & median & NM & NM & NM & NM & $\begin{array}{l}1.10(0.54- \\
2.22)\end{array}$ & 0.801 & NM & NM & NM & NM \\
\hline Svatek, 2010 & MMP2 & ElISA & median & NM & NM & NM & NM & \begin{tabular}{|l|}
$0.66(0.32-$ \\
$1.38)$
\end{tabular} & 0.272 & NM & NM & NM & NM \\
\hline Svatek, 2010 & MMP3 & ElISA & median & NM & NM & NM & NM & \begin{tabular}{|l|}
$0.97(0.50-$ \\
$1.86)$ \\
\end{tabular} & 0.916 & NM & NM & NM & NM \\
\hline Svatek, 2010 & MMP7 & ElISA & median & NM & NM & NM & NM & $\begin{array}{l}2.24(1.12- \\
4.47)\end{array}$ & 0.022 & NM & NM & NM & NM \\
\hline Svatek, 2010 & MMP8 & ElISA & median & NM & NM & NM & NM & $\begin{array}{l}1.24(0.54- \\
2.85)\end{array}$ & 0.605 & NM & NM & NM & NM \\
\hline Svatek, 2010 & MMP9 & ElISA & median & NM & NM & NM & NM & $\begin{array}{l}1.08(0.55- \\
2.14)\end{array}$ & 0.82 & NM & NM & NM & NM \\
\hline Szarvas, 2010 & MMP7 & ElISA & median & 29 & 50 & \begin{tabular}{|l|}
$2.087(1.201-$ \\
$3.627)$
\end{tabular} & 0.009 & \begin{tabular}{|l}
$2.351(1.251-$ \\
$4.418)$
\end{tabular} & 0.008 & NM & NM & \begin{tabular}{|l|}
$3.381(1.370-$ \\
$8.347)$ \\
\end{tabular} & 0.008 \\
\hline Sagara, 2010 & MMP14 & $\mathrm{IHC}$ & median & 43 & 42 & NM & NM & $\begin{array}{l}1.84(0.40- \\
8.53)\end{array}$ & 0.132 & NM & NM & NM & NM \\
\hline Vasala, 2003 & МMР9 & $\mathrm{IHC}$ & median & 33 & 54 & $\begin{array}{l}0.61 \\
1.30)\end{array}$ & 0.132 & $\begin{array}{l}1.12(0.32- \\
3.96)\end{array}$ & 0.272 & $\begin{array}{l}0.64 \\
1.11)\end{array}$ & 0.079 & NM & NM \\
\hline Slaton, 2004 & MMP9 & ISH & median & 17 & 47 & NM & NM & $\begin{array}{l}1.76(1.03 \\
3.02)\end{array}$ & 0.04 & NM & NM & NM & NM \\
\hline Vasala, 2003 & MMP2 & $\mathrm{IHC}$ & median & 35 & 19 & $\begin{array}{l}1.24(0.46- \\
3.37)\end{array}$ & 0.09 & $\begin{array}{l}1.19(0.27- \\
5.15)\end{array}$ & 0.04 & $\begin{array}{l}1.14(0.15- \\
8.66)\end{array}$ & 0.07 & NM & NM \\
\hline Durkan, 2003 & MMP9 & $\mathrm{IHC}$ & median & 64 & 42 & NM & NM & $\begin{array}{l}7.56(1.22- \\
12.36) \\
\end{array}$ & 0.022 & NM & NM & \begin{tabular}{|l|}
6.22 \\
$10.37)$
\end{tabular} & 0.005 \\
\hline Durkan, 2001 & MMP1 & ElISA & median & 21 & 110 & NM & NM & \begin{tabular}{|l|}
$5.53(1.07-$ \\
$28.58)$ \\
\end{tabular} & 0.02 & NM & NM & \begin{tabular}{|l|}
$3.23(0.56-$ \\
$18.69)$ \\
\end{tabular} & 0.04 \\
\hline $\begin{array}{l}\text { Nakopoulou, } \\
2001\end{array}$ & MMP3 & $\mathrm{IHC}$ & median & 14 & 45 & $\begin{array}{l}1.66(0.75- \\
3.71)\end{array}$ & 0.088 & NM & NM & NM & NM & NM & NM \\
\hline Hara, 2001 & MMP9 & $\begin{array}{l}\text { Northen } \\
\text { Blot }\end{array}$ & median & 16 & 35 & NM & NM & NM & NM & $\begin{array}{l}2.01(0.95- \\
3.66)\end{array}$ & 0.041 & NM & NM \\
\hline $\begin{array}{l}\text { Kanayama, } \\
1998\end{array}$ & MMP2 & \begin{tabular}{|l|} 
qRT- \\
PCR \\
\end{tabular} & mean & 21 & 20 & NM & NM & $\begin{array}{l}6.16(1.44- \\
28.86) \\
\end{array}$ & $<0.001$ & NM & NM & NM & NM \\
\hline Gohji, 1998 & MMP2 & EIA & mean & 22 & 31 & NM & NM & $\begin{array}{l}1.50(0.41- \\
5.40)\end{array}$ & 0.2224 & NM & NM & NM & NM \\
\hline Gohji, 1996 & MMP3 & EIA & mean & 23 & 30 & NM & NM & $\begin{array}{l}1.43(0.49- \\
4.14)\end{array}$ & $<0.02$ & NM & NM & NM & NM \\
\hline
\end{tabular}

HR and $95 \%$ CI calculated from survival curves or article reports.

HR, hazard ratio; CI, confidence interval; MMPs, matrix metalloproteinases; SC, survival curve; NM, not mentioned.

OS, overall survival; DSS, disease-specific survival; DFS, disease-free survival; RFS, recurrence-free survival; PFS, progression-free survival; MFS, metastasis-free survival.

IHC, immunohistochemistry; ELISA, enzyme linked immunoassay; RT-qPCR, reverse transcriptase-quantitative PCR; EIA, enzyme immunoassay; ISH, in situ hybridization.

no significant heterogeneity $\left(P=0.110, I^{2}=44.3 \%\right)$. Therefore, we concluded that MMPs overexpression was significantly associated with poor OS outcome in bladder carcinoma $(\mathrm{HR}=1.67 ; 95 \% \mathrm{CI}=1.26-2.22$; Figure $2 \mathrm{~A})$.

Furthermore, subgroup analyses were used to determine the effect of MMPs up-regulation on bladder carcinoma. A pooled analysis of three studies in the MMP7 subgroup indicated that increased MMP7 expression was significantly correlated with reduced OS (Figure 3A). However, the correlation between other MMPs and overall survival in bladder cancer patients was ambiguous due to insufficient studies. Upon samples type, using serum was significantly associated with overall death rates with a pooled HR of $2.15(95 \% \mathrm{CI}=1.51-3.05)$, whereas tissue 
showed no statistical significance $(\mathrm{HR}=1.04,95 \% \mathrm{CI}=$ 0.64-1.69; Figure 3C).

\section{DSS associated with MMPs expression}

Compared with OS, DSS can better reflect the outcomes of bladder carcinoma. Fourteen of the studies analyzed DSS. No heterogeneity between these studies was observed $\left(P=0.055, I^{2}=35 \%\right)$; thus, a fixed-effects model was applied to calculate a pooled HR along with 95\% CI. Our analysis revealed that high expression of MMPs correlated with shorter DSS $(\mathrm{HR}=1.66$, $95 \% \mathrm{CI}=1.38-2.01$; Figure $2 \mathrm{~B}$ ). In addition, characteristics like MMPs type, assay methods, dominant ethnicity, and type of samples were divided into subgroups for analysis; calculated results were exhibited in detail in Figure 4.

\section{DFS/RFS associated with MMPs expression}

In total, six studies included in DFS/RFS analysis indicated no valuable role of increased MMPs expression for predicting DFS/RFS $(\mathrm{HR}=1.21,95 \% \mathrm{CI}=0.96-1.53$, Figure $2 \mathrm{C}$ ), which was determined by a fixed-effects model $\left(P=0.080, I^{2}=49.1 \%\right)$. In anglysis of pathology subgroup, Olsson in 2012 and Hara in 2001 focusing on non muscle-invasive bladder cancer (NMIBC) revealed that MMPs predicted high risk of recurrence $(\mathrm{HR}=1.49,95 \% \mathrm{CI}=1.13-1.96$, Figure 5E). However, other three studies did not differentiate muscle-invasive disease (MIBC) and non muscle-invasive (NMIBC) and obtained insignificant results. Furthermore, results of other subgroup analysis were also depicted in Figure 5.

\section{Cancer progression associated with MMPs expression}

Generally, bladder cancer progression was evaluated by combining tumor recurrence and metastasis. In total, five articles investigating four different MMPs types (MMP1, MMP7, MMP9, and MMP11) reported a relationship between abnormal levels of MMPs and bladder tumor progression. A pooled HR (3.03) and 95\%

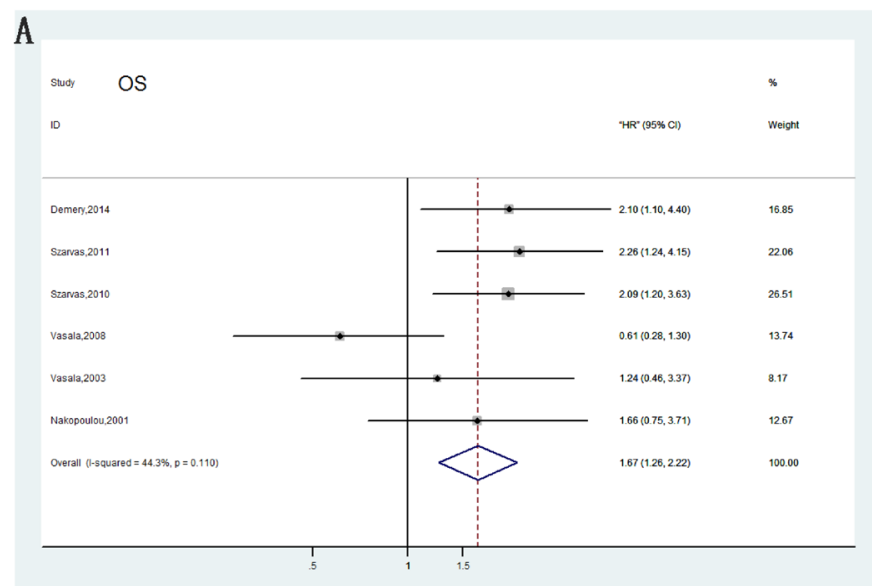

B

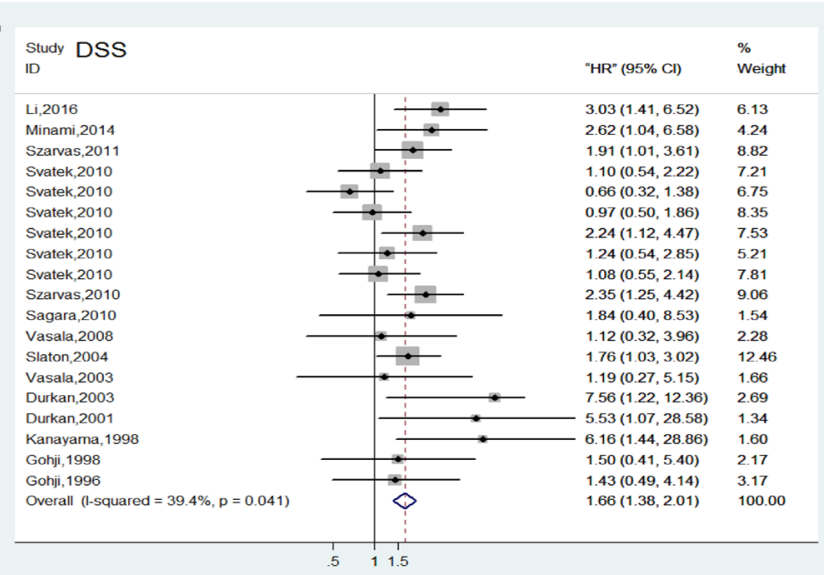

C

D
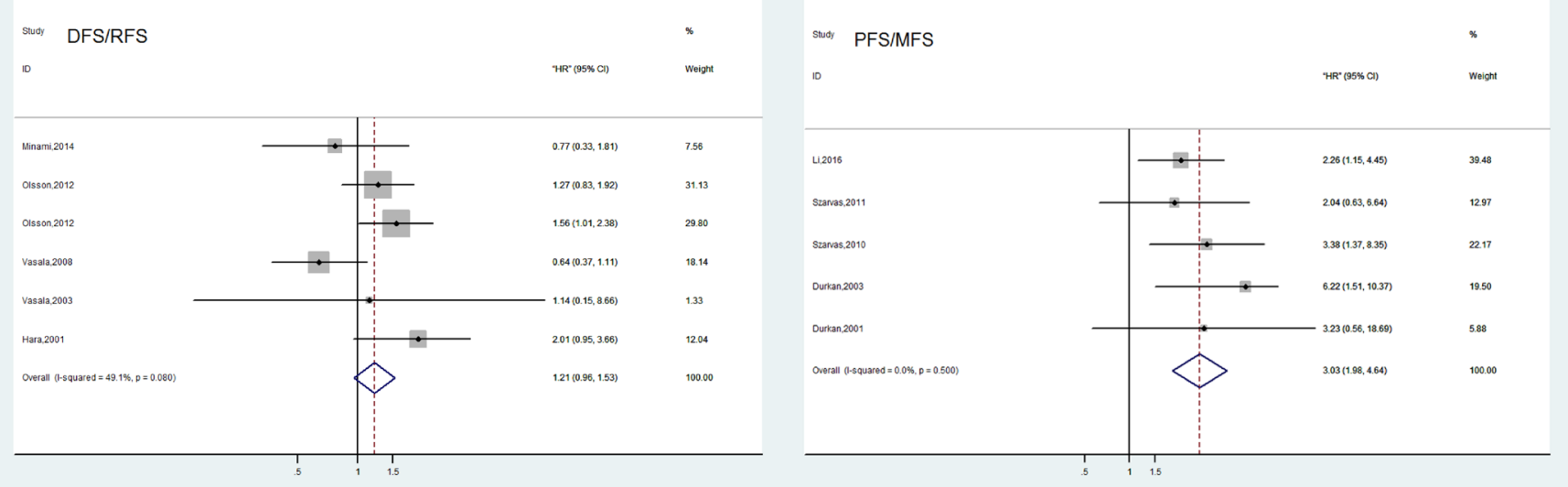

Figure 2: Forrest plots of merged analyses of high MMP expression as compared to low expression. Survival data are reported as overall survival (OS) A. and disease-specific survival (DSS) or cancer-specific survival (CSS) B., disease-free survival (DFS) or relapse-free survival (RFS) C., progress-free survival (PFS) or metastasis-free survival (MFS) D. 


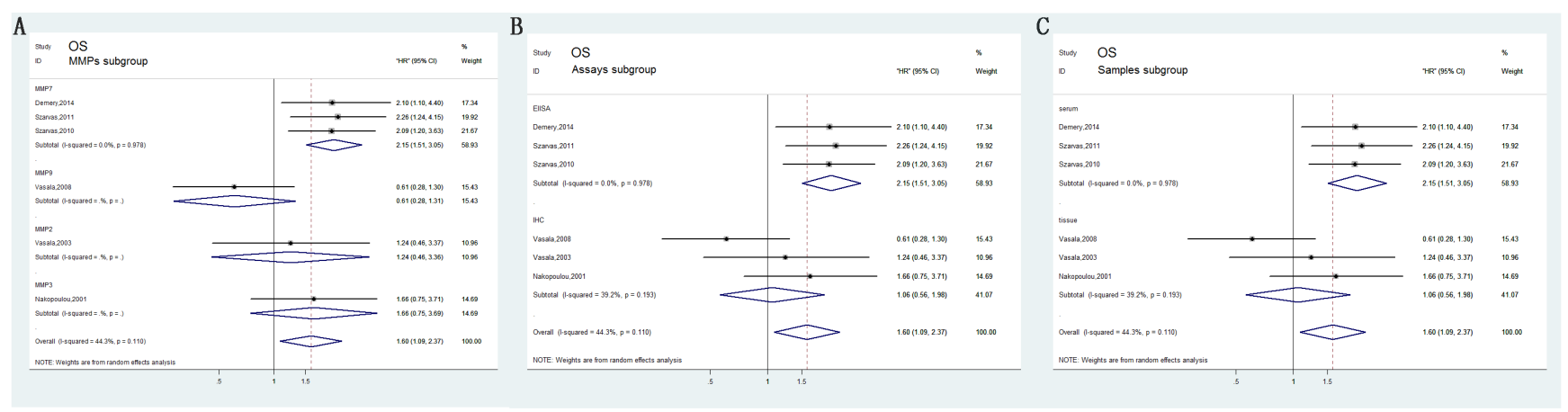

Figure 3: Forest plots of subgroup analysis of the OS. A. stratified by MMPs subgroups; B. stratified by Assay methods; C. stratified by Sample subgroups.
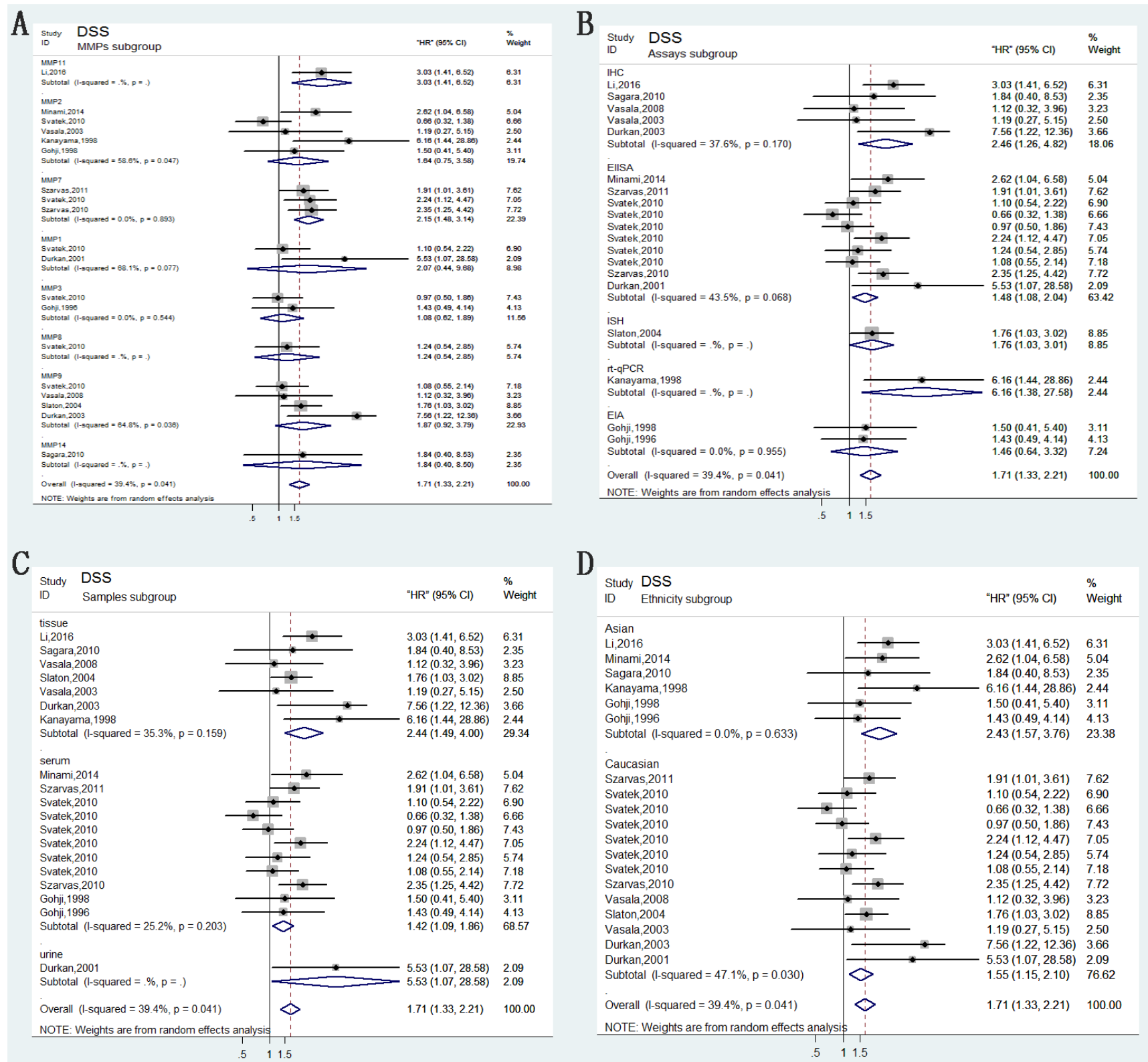

Figure 4: Forest plots of subgroup analysis of the DSS/CSS. A. stratified by MMPs subgroups; B. stratified by Assay methods; C. stratified by Sample subgroups; D. stratified by Ethnicity subgroups. 
CI (1.98-4.64) were obtained with no heterogeneity (Figure 2D). Our meta-analysis revealed the association between abnormal MMPs expression and cancer progression. Stratified analyses were performed for MMPs, sample types, and assay methods, and similar results were obtained (Figure 6).

\section{Sensitivity analyses}

In order to reduce the effect of individual studies on final conclusions and evaluate the stability of results, a sensitivity analysis was performed by fixed-effect model. This test indicated that for DSS, DFS/RFS, and PFS/ MFS, our results did not tend to exhibit alterations when an individual study was excluded (Figure 7). However, our analysis discovered that Vasala's (2008) investigation had an obvious influence on OS result [17]. After excluding this data, a more convincing pooled $\mathrm{HR}$ and $95 \%$ CI was obtained $(\mathrm{HR}=1.96,95 \% \mathrm{CI}=1.45-2.67$, Figure 9A $)$ and heterogeneity decreased significantly $\left(P=0.864, I^{2}=0 \%\right)$. In addition, results of sensitivity analyses and publication bias no longer changed anymore (Figure 9B, 9C).

\section{Publication bias}

In this meta-analysis, publication bias was evaluated using Begg's funnel plots and the Egger test (Figure 8). For the pooled analyses of OS, DSS, DFS/RFS, and PFS/ MFS, $P$ values of the Egger test were $0.076,0.728,0.887$, and 0.725 , respectively. Adding to this, the funnel plots were symmetrical and no obvious publication bias was identified.

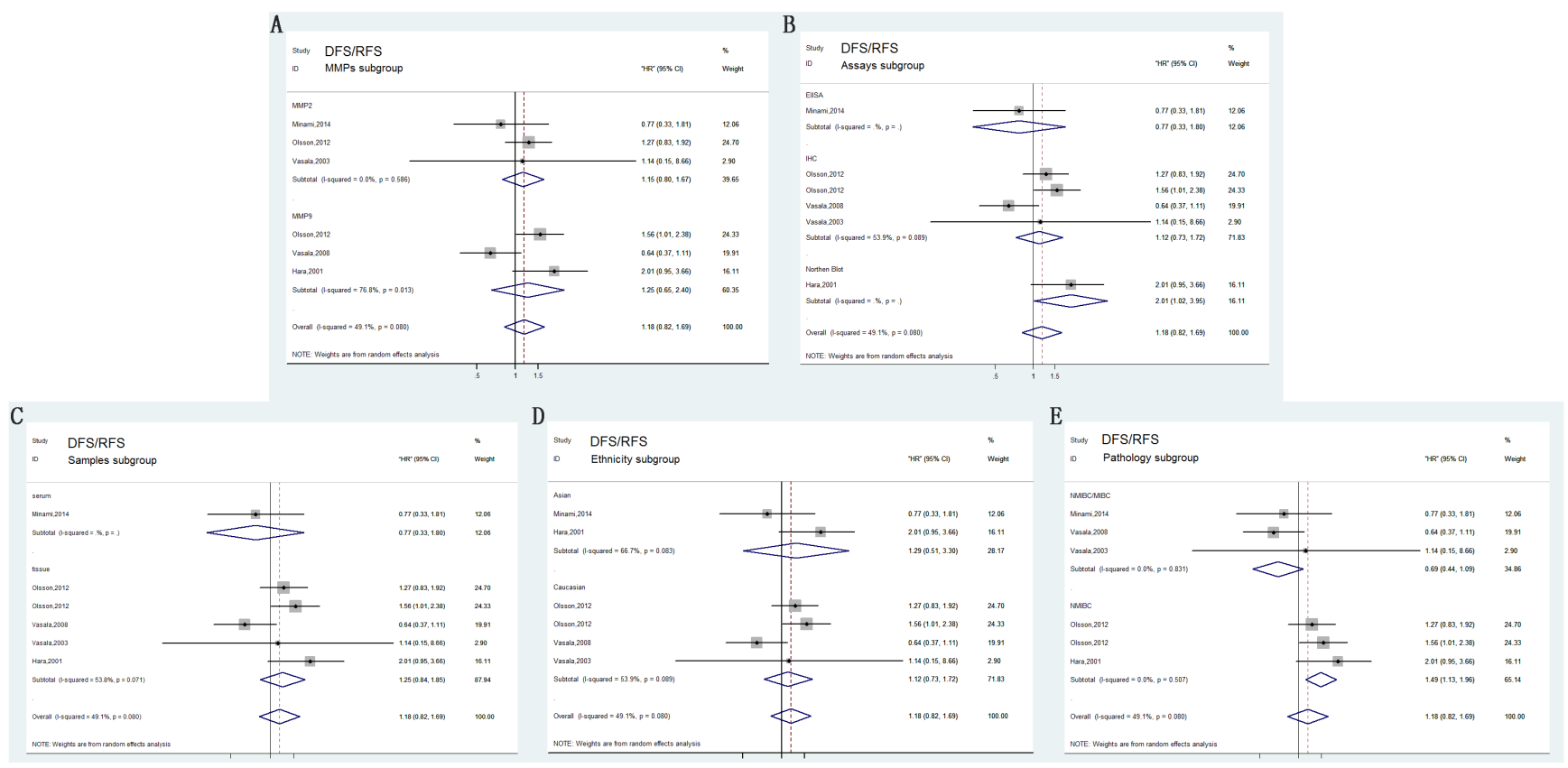

Figure 5: Forest plots of subgroup analysis of the DFS/RFS. A. stratified by MMPs subgroups; B. stratified by Assay methods; C. stratified by Sample subgroups; D. stratified by Ethnicity subgroups; E. stratified by Pathology subgroups.

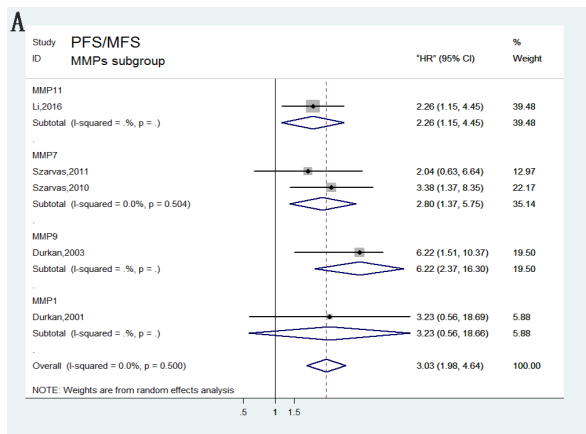

Figure 6: Forest plots of subgroup analysis of the PFS/MFS. A. stratified by MMPs subgroups; B. stratified by Assay methods; C. stratified by Sample subgroups.
C
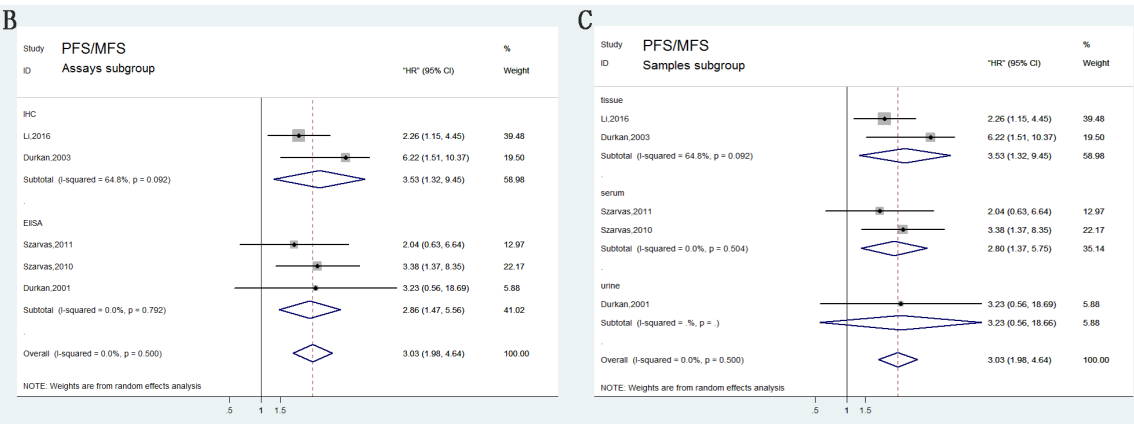


\section{DISCUSSION}

Ranking as the ninth most common carcinoma in 2008 , bladder cancer is the most frequent neoplasm of the urinary tract worldwide [18, 19]. Although remarkable advance in treatment has been made recently, high mortality, recurrence rates, and poor prognosis are still the major concerns. Even after early radical cystectomy and reasonable drug therapy, quite a few patients with bladder carcinomas experience primary invasion and metastasis [20]. Transitional cell tumors account for $95 \%$ of bladder carcinoma types. The majority of patients develop recurrences after surgery and tend to progress to an advanced stage. Despite various combined therapy approaches, bladder carcinoma remains progressive with high relapse rates worldwide [21-22]. Therefore, investigating factors that are associated with tumor infiltration and metastasis may provide some appropriate therapies for different cases and judge their prognosis. Over the years, numerous potential biomarkers have been tested for predicting outcomes of bladder cancer patients.

Extracellular matrix (ECM) can provide structural support for cells and develop tissue frameworks that get involved in a dynamic process of interacting with cells and regulating their functions. Recent studies focusing on the mechanism of metastatic tumor dissemination have verified that ECM plays a key role in the multistep process of invasion and metastasis [23, 24]. In this process, tumor cells must secrete proteases or enhance relevant protease activities and possess the ability to degrade the ECM of the basement membrane and the intercellular matrix. The interaction between tumor and ECM is a prerequisite for tumor growth, and plays an important role in both the prognosis and progression of bladder cancer $[25,26]$.

The proteases secreted by tumor cells leading to the degradation of ECM are MMPs. Currently, MMPs family consists of 25 extracellular zinc endopeptidases, and they are the most important members of the proteases family [27]. MMPs family contains various subgroups such as: collagenases, gelatinases, stromelysins, matrilysins, membrane-type MMPs, and other subtypes. Among all kinds of the proteases listed above, MMP1, MMP8, and MMP13 are collagenases; MMP2 and MMP9 are gelatinases; MMP3, MMP10, MMP11, and MMP12 are stromelysins; while MMP7, MMP16, MMP14, MMP15, and MMP-26 are matrilysins, membrane-type MMPs, and
A

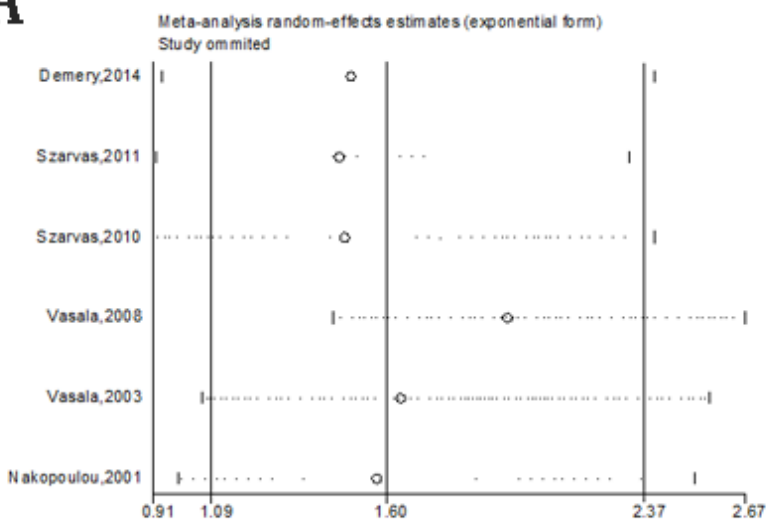

B

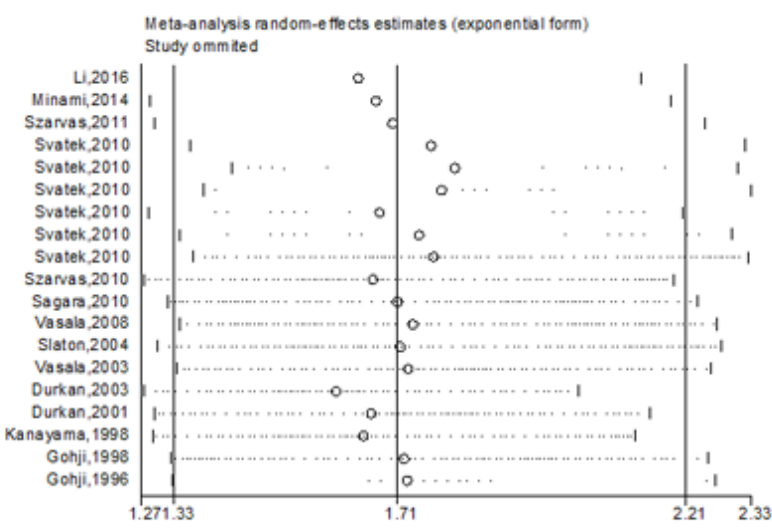

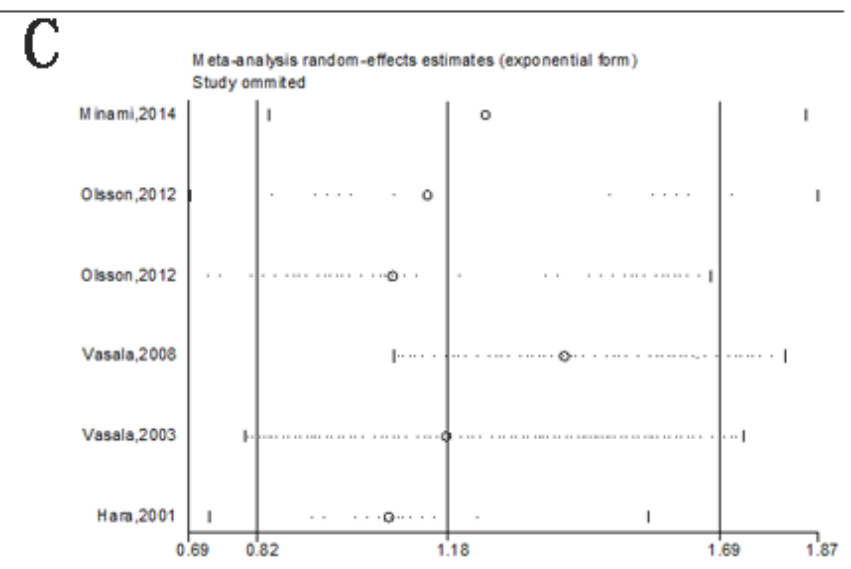

D

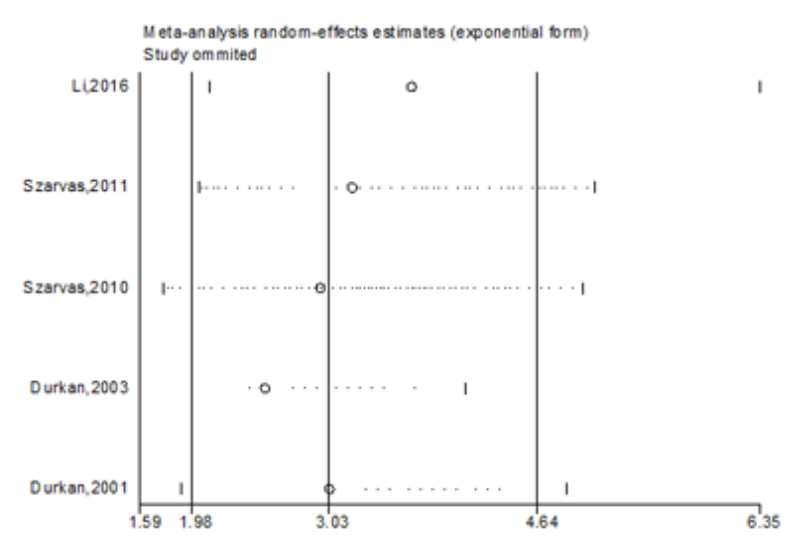

Figure 7: Sensitivity analysis under the specific model. A. effect of individual studies on the pooled HR for OS; B. effect of individual studies on the pooled HR for DSS/CSS; C. effect of individual studies on the pooled HR for DFS/RFS. D. effect of individual studies on the pooled HR for PFS/MFS. 
other subtypes [28]. Previous studies have proven that MMPs can eliminate most of the ECM components, such as native collagen types, gelatin, fibronectin, and others [27]. In addition, MMPs have been considered as essential elements for invasive tumor growth and metastasis of bladder carcinoma [29]. In accordance with this, abnormal expression of MMPs was identified as a prognostic indicator in patients with bladder carcinoma [30, 31]. However, up to date most of clinical investigations focused on partial populations and specimens, which are unable to reveal the value of MMPs in survival outcomes of bladder cancer. Thus, we conducted this systematic review and meta-analysis to clarify the status of MMPs in bladder cancer populations. Although some review articles have investigated MMPs polymorphisms and their clinical association with the risk of bladder carcinoma, this is the first systematic review and meta-analysis evaluating the association between abnormal MMPs expression and patients' outcomes [16, 30].

In this meta-analysis, we used subgroup, sensitivity, and heterogeneity analysis to explore the effects of main characteristics in the included studies. Our results indicated that overexpression of MMPs is a prognostic factor predicting poor bladder cancer survival. A pooled HR of 1.67 and $95 \%$ CI (1.26-2.22) in the OS analysis
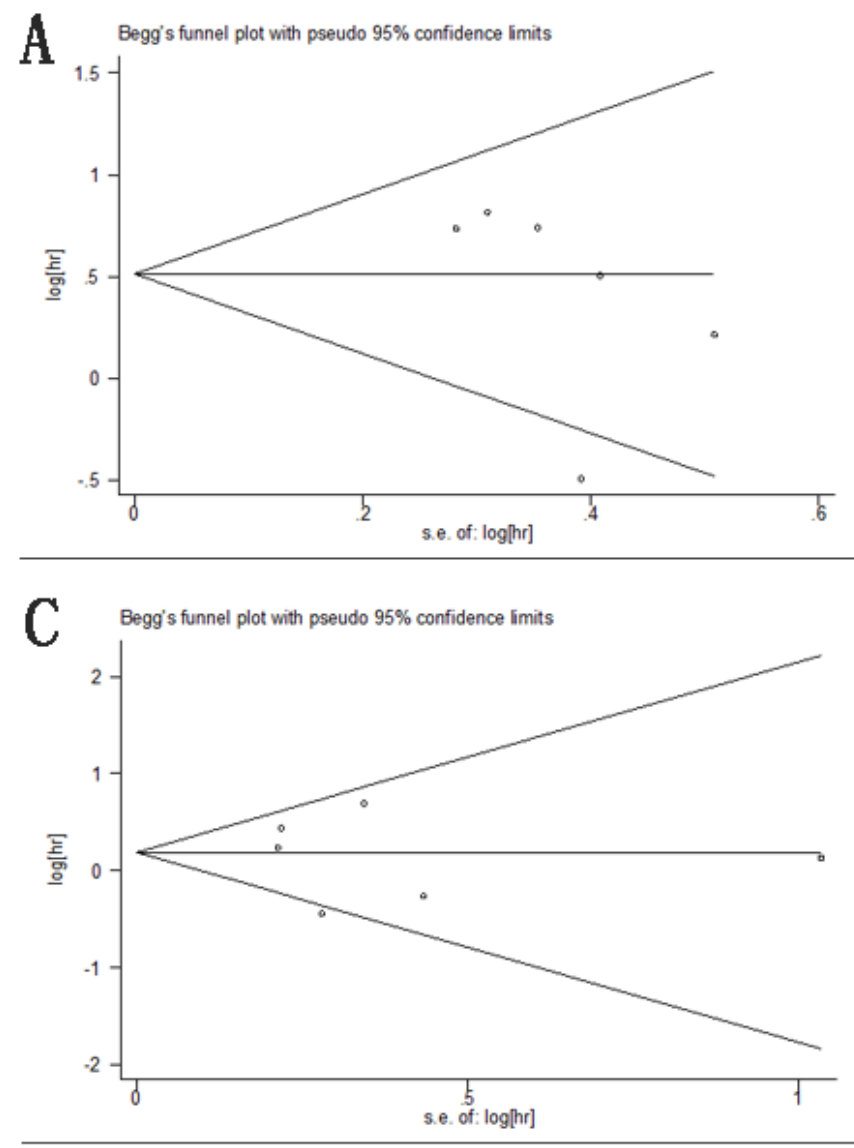

demonstrated that increased MMPs expression correlates with poor outcome in bladder cancer.

In contrast to OS, DSS can more accurately reflect the cause specific mortality of cancer, by excluding those that died from non-tumorous causes, such as cardiovascular, cerebrovascular, or others. According to the study of Gschwend et al. on bladder cancer patients undergoing radical cystectomy, the outcome is best characterized by DSS rather than OS, and they defined DSS as a better predictor for survival analyses [19, 32]. Our calculation of DSS/CSS analyses revealed a pooled HR of $1.66(95 \% \mathrm{CI}=1.38-2.01)$, which demonstrated that high MMPs expression was associated closely with higher risk of disease-specific death risk $\left(P=0.041, I^{2}\right.$ $=39.4 \%$ ). In stratified analyses, we found that multiple MMPs tended to be prognostic for a poor bladder cancerspecific survival, suggesting the specific relationship between MMPs and survival rates. Furthermore, subgroup analyses based on assay methods, sample types, and ethnicity provided a quite unified conclusion that upregulated MMPs predict inferior DSS. However, we could not ignore the individual study influence on the overall results. Among all the included studies, Svatek et al. in 2010 detected plasma MMP concentrations (MMP1, 2, 3, $7,8,9$, and 12) in 135 bladder cancer patients, reporting
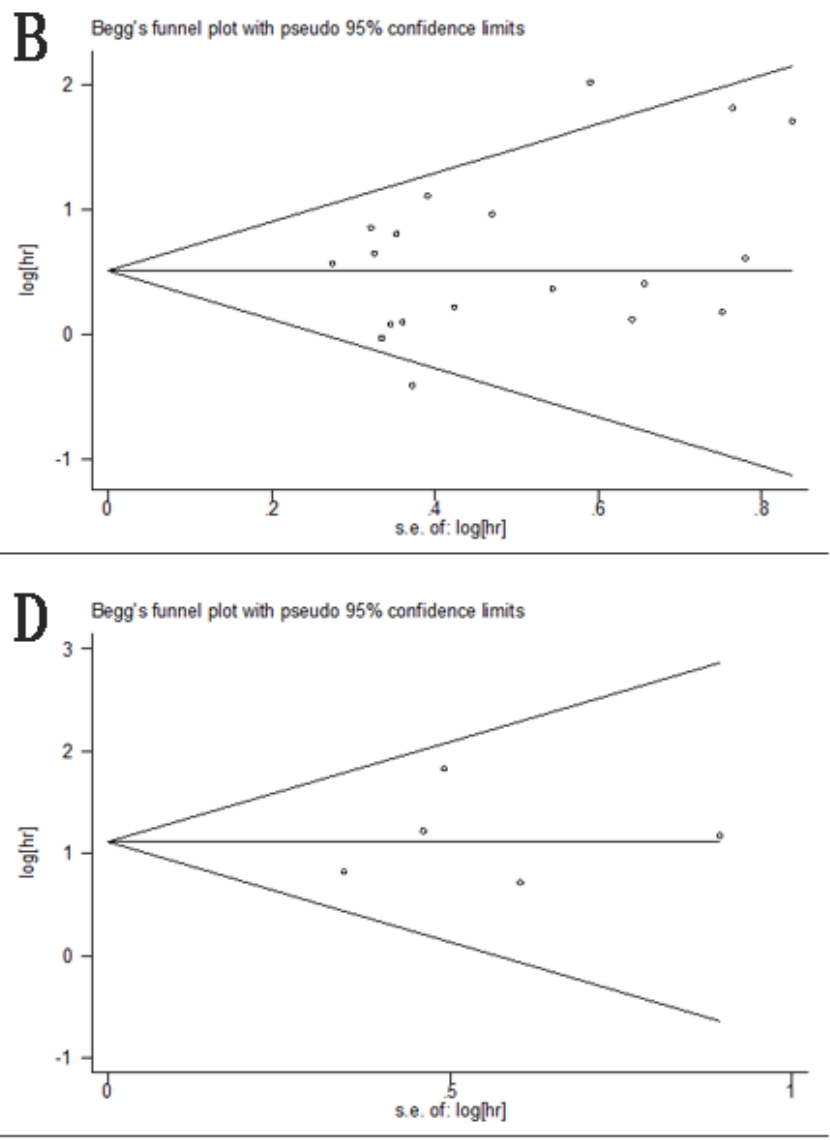

Figure 8: Begg's funnel plots of publication bias test. A. OS; B. DSS/CSS; C. DFS/RFS; D. PFS/MFS. 
that high MMP7 levels were significantly associated with poor $\mathrm{CSS}$ rates $(\mathrm{HR}=2.24,95 \% \mathrm{CI}=1.12-4.47 ; P=$ 0.022 ). Other MMPs did not show a statistically significant association $(P>0.05)$. In stratified analysis by MMPs type, the prognostic function of different MMPs was still controversial and unstable. We attributed this to the different molecular structures, limited relevant research, and therefore the stability of the conclusion needs to be further verified.

Furthermore, DFS/RFS analysis suggested that high MMPs expression did not develop a pivotal role in recurrence of bladder cancer $(\mathrm{HR}=1.21,95 \% \mathrm{CI}=0.96$ 1.53). However, subgroup analysis of pathology stage indicated that MMPs overexpression enhanced high relapse risk in patients with NMIBC but not MIBC. NMIBC patients treated with transurethral resection might account for the high recurrence rates, in contrast to MIBC patients undergoing radical surgery [21]. Other stratified analysis failed to achieve statistical significance. Subsequently, five studies focusing on PFS/MFS analysis showed that increased MMPs expression indicated high risk of tumor progression and metastasis $(\mathrm{HR}=3.03,95 \%$ $\mathrm{CI}=1.98-4.64)$.

These significant findings implied the predictive role of MMPs in poor outcome of bladder carcinomas [3335]. The majority of current investigations have provided strong evidence for the oncogenic role of MMPs in human bladder cancer. However, due to the limited literature quantities included in this meta-analysis, additional high-quality studies are still needed to further verify the conclusion.

Besides, there are seven included studies reported the association between MMP2 and bladder cancer, and six investigations focused on MMP9. Interesting, MMP2, together with MMP9, which belong to the gelatinases family, can degrade a major component of basement membrane named type IV collagen [9, 36, 37]. Contradictory results have been reported in previous studies about the prognostic value of MMP2 in bladder cancer. Vasala et al. and Kanayama et al. reported upregulated MMP2 expression as a significant risk factor for poor DSS in patients with bladder carcinoma [38,
39]. However, Svatek et al. detected the concentration of MMP2 by ELISA, and found that MMP2 levels were unrelated to prognosis. These contradictory studies highlight the urgent necessity for the standardization of prognostic marker analysis in order to provide more convincing conclusion. Similar to MMP2, the prognostic role of MMP9 is equally disputed. In this meta-analysis, we found that most of articles regarded MMP9 as a prognostic factor for poor outcome while Vasala et al. and Svatek et al. found no correlation between MMP9 and outcomes [17, 40]. Thus, the relevance of MMP9 overexpression is highly questionable and still needs further confirmation. Our DFS/RFS analyses showed that only MMP2 and MMP9 were related to disease recurrence in patients. In consistent with four studies performing DFS/RFS analysis, Olsson et al. reported that abnormal expression of MMP2 and MMP9 were associated with a high risk of tumor recurrence in patients with stage T1 bladder cancer [41]. Vasala et al. and Hara et al. found that high MMP2 and MMP9 expression correlated with poor survival and high recurrence rate. In contrast, other two included articles reported that MMP2 and MMP9 was related to a low risk of recurrence [17, 4243]. As previously explained, limitations of research quantities and neoplasm stages might account for these discrepancies. Besides, none of other MMPs in this meta-analysis were found to be associated with tumor recurrence. Mechanism and role of other MMPs involved in bladder carcinoma's recurrence is still not clear and requires further confirmation.

To conclude, our results indicated that detection of abnormal MMP levels is of great value in prognosis of bladder carcinoma patients. Although extensive retrieval was conducted in analysis, along with rigorous statistical analysis, our conclusion still needs cautious interpretation for several reasons. First, on account of limitation of articles reporting OS/DFS/PFS in this meta-analysis, the reliability and tightness of pooled HRs is not fully adequate. Second, several different assays such as IHC, ELISA, RT-qPCR, and northern blot were used to detect the concentration of MMPs in different samples. To some extent, methodological differences among individual

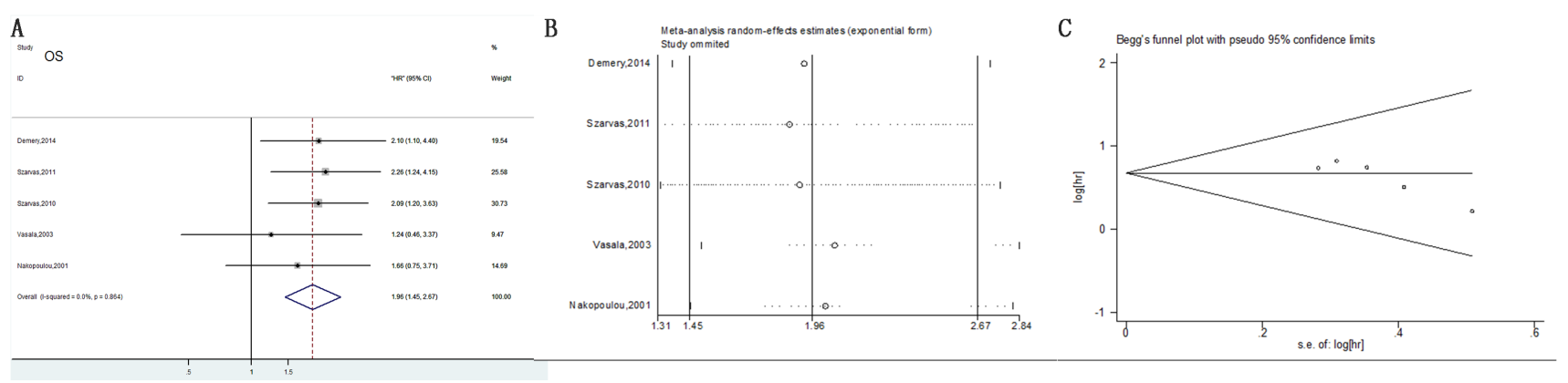

Figure 9: Meta-analysis of OS following exclusion of data from Vasala et al. (2008). A. Forest plots analysis of OS; B. Sensitivity analysis to confirmation of results' stability; C. Publication bias to the evaluation of studies' symmetry. 
investigations may contribute to inevitable heterogeneity. Additionally, even most of current studies have maintained a median or mean value as the cut-off point, a recognized MMPs expression level to define a single value was still difficult to achieve. Third, no independent investigation on Negroid was included in this meta-analysis, which might undermine the comprehensiveness to some extent. Furthermore, no prospective studies were available for this meta-analysis, and it might weaken the validity of results. Taking these limitations into account, the prognostic value of MMPs in bladder neoplasm might be overestimated. Our results should be interpreted rigorously because of these imperfections.

In conclusion, our analysis indicated that high MMPs expression significantly predicted poor OS/ DSS/PFS in bladder cancer populations. However, overexpression of MMPs did not function as key factiors in bladde cancer relapse. Besides, only MMP2 and MMP9 were found to involve into cancer. Given the current insufficient evidence, further high quality investigations and large-scale studies are required to comfirm our findings, which can also develop more clinical applications and provide accurate prognostic information.

\section{MATERIALS AND METHODS}

\section{Search strategy}

To evaluate the specific role of MMPs in bladder carcinomas, we used several online databases including PubMed, EMBASE and the Web of Science to search relevant literature published through June 2016. Primarily, only studies published in English could be included to this meta-analysis. For the literature retrieval, following medical subject and text words were used: "bladder cancer" or "bladder carcinoma" or "bladder Neoplasm" or "bladder Tumor", "MembraneType Matrix Metalloproteinase" or "MMPs" or "Matrix metalloproteinase" and "prognostic" or "prognosis" or "survival" or "outcome" or "recurrence" or "relapse". In addition, following criteria should be considered to select the literatures: (1) an emphasis to human beings, (2) a relationship between MMPs and prognosis or survivals of bladder cancer. We also searched for Chinese articles to better understanding the association between MMPs and bladder neoplasm. Finally, no Chinese studies were meeting the inclusion criteria. Afterwards, articles published was retrieved for further checking. Additionally, we also screened the references of retrieved articles for any possible eligible studies.

\section{Quality assessment}

MMPs are a family including multiple MMP types, such as: MMP1, MMP2, MMP7, MMP9, MMP11, MMP14 and so forth. The aim of this meta-analysis is to analyses the value of MMPs family to prognosis of patients with bladder carcinoma. Therefore, studies were selected only the patients were undergoing follow-up intervention and in whom expression levels of MMPs were measured. To evaluate the retrieval studies, articles published must be an original clinical study, for instance a case-control study or a randomized controlled trial. In addition, we also recorded following information: (1) the study population and country, (2) the type of MMPs, (3) dominant assay method to determine MMPs: ELISA, IHC or RT-qPCR, etc (4) the prognosis or survival assessment, (5) the detected sample and cut-off point of MMPs, (6) the follow-up period of patients, et al (Table 1). Sensitivity analyses and published bias were performed to promote the quality of this meta-analysis.

\section{Data selection}

All data from eligible studies were extracted independently, ambiguous data were reviewed in detail. Extracted data elements comprised as follows: (1)the first author's name and publishing year; (2) the MMPs type of study, (3) the population, nationality, dominant ethnicity and detected sample; (3) the investigating method, cutoff value and follow-up time; (4) Hazard ratio associated with overexpression MMPs for overall survival (OS), disease-specific survival (DSS), disease-free survival (DFS)/recurrence-free survival (RFS) and progression-free survival (PFS)/metastasis-free survival (MFS) along with their $95 \% \mathrm{CI}$ and $\mathrm{P}$ values, (5) the median or mean age of the patient. If HR and $95 \%$ CIs were not provided in studies, we extracted them from graphical survival curves using Engauge Digitizer version 4.1 [44, 45]. All relevant data mentioned above were comprehensively shown in Table 1 and Table 2.

\section{Statistical analysis}

According to the heterogeneity of pooled studies, we choose the fixed-effects model (Mantel-Haenszel method) or the random-effects model (DerSimonianLaird method) to analyse the data above. Heterogeneity test for pooled HRs was calculated by Cochran Q-test and Higgins I-squared statistic $\left(I^{2}\right)$. A random-effects model (DerSimonian-Laird method) was applied if $P<0.10$ or $I^{2}>50 \%$, otherwise a fixed-effects model (Mantel-Haenszel method) was used instead [46]. Additionally, subgroup analysis based on similar factors were performed to reduce the influence of heterogeneity. We used Begg's 
funnel plot and Egger linear regression test with a funnel plot to evaluate the publication bias of eligible literature [47]. All statistical analyses were conducted with Stata12 (StataCorp LP, College Station, TX, USA), Review Manager (RevMan) V.5.3 (Copenhagen: the NordicCochrane Centre, the Cochrane Collaboration, 2014), Microsoft Excel (V.2013, Microsoft Corporation, Redmond, Washington, USA).

\section{ACKNOWLEDGMENTS AND FUNDING}

This work is supported by the grant from National Natural Science Foundation of China (81200467; 81402104).

\section{CONFILCTS OF INTEREST}

The authors declare no conflict of interest.

\section{REFERENCES}

1. Ploeg M, Aben KK, Kiemeney LA. The present and future burden of urinary bladder cancer in the world. World J Urol. 2009; 27:289-93.

2. Ferlay J, Shin HR, Bray F, Forman D, Mathers C, Parkin DM. Estimates of worldwide burden of cancer in 2008: GLOBOCAN 2008. Int J Cancer. 2010; 127:2893-917.

3. Nepple KG, O'Donnell MA. The optimal management of T1 high-grade bladder cancer. Can Urol Assoc J. 2009; 3:S188-92.

4. Bryan RT. Bladder cancer and cancer stem cells: basic science and implications for therapy. Sci World J. 2011; 11:1187-94.

5. Kaufman DS, Shipley WU, Feldman AS. Bladder cancer. Lancet. 2009; 374:239-49.

6. Zhao M, He XL, Teng XD. Understanding the molecular pathogenesis and prognostics of bladder cancer: an overview. Chin J Cancer Res. 2016; 28:92-98.

7. Solomon JP, Hansel DE. Prognostic factors in urothelial carcinoma of the bladder: histologic and molecular correlates. Adv Anat Pathol. 2015; 22:102-12.

8. Egeblad M, Werb Z. New functions for the matrix metalloproteinases in cancer progression. Nat Rev Cancer. 2002; 2:161-74.

9. Bode W, Maskos K. Structural studies on MMPs and TIMPs. Methods Mol Biol. 2001; 151:45-77.

10. Agewall S. Matrix metalloproteinases and cardiovascular disease. Eur Heart J. 2006; 27:121-22.

11. Liu P, Sun M, Sader S. Matrix metalloproteinases in cardiovascular disease. Can J Cardiol. 2006; 22 Suppl B:25B-30B

12. Sierevogel MJ, Pasterkamp G, de Kleijn DP, Strauss BH. Matrix metalloproteinases: a therapeutic target in cardiovascular disease. Curr Pharm Des. 2003; 9:1033-40.
13. Westermarck J, Kähäri VM. Regulation of matrix metalloproteinase expression in tumor invasion. FASEB J. 1999; 13:781-92.

14. Shen W, Xi H, Wei B, Chen L. The prognostic role of matrix metalloproteinase 2 in gastric cancer: a systematic review with meta-analysis. J Cancer Res Clin Oncol. 2014; 140:1003-09.

15. Jezierska A, Motyl T. Matrix metalloproteinase-2 involvement in breast cancer progression: a mini-review. Med Sci Monit. 2009; 15:RA32-40.

16. Szarvas $T$, vom Dorp F, Ergün $S$, Rübben H. Matrix metalloproteinases and their clinical relevance in urinary bladder cancer. Nat Rev Urol. 2011; 8:241-54.

17. Vasala K, Pääkko P, Turpeenniemi-Hujanen T. Matrix metalloproteinase-9 (MMP-9) immunoreactive protein in urinary bladder cancer: a marker of favorable prognosis. Anticancer Res. 2008; 28:1757-61.

18. Nagata M, Muto S and Horie S. Molecular Biomarkers in Bladder Cancer: Novel Potential Indicators of Prognosis and Treatment Outcomes. Dis Markers. 2016; 2016:8205836.

19. Gschwend JE, Dahm P, Fair WR. Disease specific survival as endpoint of outcome for bladder cancer patients following radical cystectomy. Eur Urol. 2002; 41:440-48.

20. Anghel RM, Gales LN, Trifanescu OG. Outcome of urinary bladder cancer after combined therapies. J Med Life. 2016; 9:153-59.

21. Chou R, Selph SS, Buckley DI, Gustafson KS, Griffin JC, Grusing SE, Gore JL. Treatment of muscle-invasive bladder cancer: A systematic review. Cancer. 2016; 122:842-51.

22. Arcangeli G, Strigari L, Arcangeli S. Radical cystectomy versus organ-sparing trimodality treatment in muscleinvasive bladder cancer: A systematic review of clinical trials. Crit Rev Oncol Hematol. 2015; 95:387-96.

23. Pittayapruek P, Meephansan J, Prapapan O, Komine M, Ohtsuki M. Role of Matrix Metalloproteinases in Photoaging and Photocarcinogenesis. Int J Mol Sci. 2016; 17:6.

24. Harisi R, Jeney A. Extracellular matrix as target for antitumor therapy. Onco Targets Ther. 2015; 8:1387-98.

25. Aitken KJ, Bägli DJ. The bladder extracellular matrix. Part I: architecture, development and disease. Nat Rev Urol. 2009; 6:596-611.

26. Faurobert E, Bouin AP, Albiges-Rizo C. Microenvironment, tumor cell plasticity, and cancer. Curr Opin Oncol. 2015; 27:64-70.

27. Overall CM. Molecular determinants of metalloproteinase substrate specificity: matrix metalloproteinase substrate binding domains, modules, and exosites. Mol Biotechnol. 2002; 22:51-86.

28. Choi YD, Cho NH, Ahn HS, Cho KS, Cho SY, Yang WJ. Matrix metalloproteinase expression in the recurrence of superficial low grade bladder transitional cell carcinoma. J Urol. 2007; 177:1174-78.

29. Durkan GC, Nutt JE, Rajjayabun PH, Neal DE, 
Lunec J, Mellon JK. Prognostic significance of matrix metalloproteinase-1 and tissue inhibitor of metalloproteinase-1 in voided urine samples from patients with transitional cell carcinoma of the bladder. Clin Cancer Res. 2001; 7:3450-56.

30. Wieczorek E, Wasowicz W, Gromadzinska J, Reszka E. Functional polymorphisms in the matrix metalloproteinase genes and their association with bladder cancer risk and recurrence: a mini-review. Int J Urol. 2014; 21:744-52.

31. Kanayama H. Matrix metalloproteinases and bladder cancer. J Med Invest. 2001; 48:31-43.

32. Lee CT, Madii R, Daignault S, Dunn RL, Zhang Y, Montie JE, Wood DP Jr. Cystectomy delay more than 3 months from initial bladder cancer diagnosis results in decreased disease specific and overall survival. J Urol. 2006; 175:1262-67.

33. Zeng FC, Cen S, Tang ZY, Kang XL. Elevated matrix metalloproteinase-9 expression may contribute to the pathogenesis of bladder cancer. Oncol Lett. 2016; 11:221322.

34. Srivastava P, Kapoor R, Mittal RD. Association of single nucleotide polymorphisms in promoter of matrix metalloproteinase-2, 8 genes with bladder cancer risk in Northern India. Urol Oncol. 2013; 31:247-54.

35. Srivastava P, Mandhani A, Kapoor R, Mittal RD. Role of MMP-3 and MMP-9 and their haplotypes in risk of bladder cancer in North Indian cohort. Ann Surg Oncol. 2010; 17:3068-75.

36. Donmez G, Sullu Y, Baris S, Yildiz L, Aydin O, Karagoz F, Kandemir B. Vascular endothelial growth factor (VEGF), matrix metalloproteinase-9 (MMP-9), and thrombospondin-1 (TSP-1) expression in urothelial carcinomas. Pathol Res Pract. 2009; 205:854-57.

37. Grignon DJ, Sakr W, Toth M, Ravery V, Angulo J, Shamsa F, Pontes JE, Crissman JC, Fridman R. High levels of tissue inhibitor of metalloproteinase-2 (TIMP-2) expression are associated with poor outcome in invasive bladder cancer. Cancer Res. 1996; 56:1654-59.

38. Vasala K, Pääkkö P, Turpeenniemi-Hujanen T. Matrix metalloproteinase-2 immunoreactive protein as a prognostic marker in bladder cancer. Urology. 2003; 62:952-57.
39. Kanayama H, Yokota K, Kurokawa Y, Murakami Y, Nishitani M, Kagawa S. Prognostic values of matrix metalloproteinase-2 and tissue inhibitor of metalloproteinase-2 expression in bladder cancer. Cancer. 1998; 82:1359-66.

40. Svatek RS, Shah JB, Xing J, Chang D, Lin J, McConkey DJ, Wu X, Dinney CP. A multiplexed, particlebased flow cytometric assay identified plasma matrix metalloproteinase-7 to be associated with cancer-related death among patients with bladder cancer. Cancer. 2010; 116:4513-19.

41. Olsson H, Hultman P, Monsef N, Rosell J and Jahnson S. Immunohistochemical evaluation of cell cycle regulators: impact on predicting prognosis in stage $\mathrm{t} 1$ urinary bladder cancer. Isrn Urol. 2012; 2012:379081.

42. Minami S, Nagashio R, Ueda J, Matsumoto K, Goshima N, Hattori M, Hachimura K, Iwamura M, Sato Y. Detection of tumor-associated antigens in culture supernatants using autoantibodies in sera from patients with bladder cancer. Biomed Res. 2014; 35:25-35.

43. Hara I, Miyake H, Hara S, Arakawa S, Kamidono S. Significance of matrix metalloproteinases and tissue inhibitors of metalloproteinase expression in the recurrence of superficial transitional cell carcinoma of the bladder. $\mathrm{J}$ Urol. 2001; 165:1769-72.

44. Williamson PR, Smith CT, Hutton JL, Marson AG. Aggregate data meta-analysis with time-to-event outcomes. Stat Med. 2002; 21:3337-51.

45. DerSimonian R, Laird N. Meta-analysis in clinical trials revisited. Contemp Clin Trials. 2015; 45:139-45.

46. DerSimonian R, Kacker R. Random-effects model for metaanalysis of clinical trials: an update. Contemp Clin Trials. 2007; 28:105-14.

47. Egger M, Davey Smith G, Schneider M, Minder C. Bias in meta-analysis detected by a simple, graphical test. BMJ. 1997; 315:629-34. 